\title{
Effective axial load as a function of the ultimate stress state of rocks to be drilled
}

\author{
L.K. Gorshkov \\ Saint-Petersburg military space Academy A. F. Mozhaysky, Saint-Petersburg, Russia
}

\author{
A.N. Dmitriev \\ St. Petersburg mining University, St. Petersburg, Russia
}

\begin{abstract}
This paper presents the study of the mechanism of well deepening in diamond drilling. Destruction of rocks under diamond drilling is represented by a set of deformation processes arising in rocks when destroying efforts are applied. Modern requirements to the technology and economic feasibility of drilling operations suggest continuous improvement in the field of the mechanism of bottom rock breaking. The article proposes a procedure to analyze situations at well bottom drilling deeper per a revolution of the diamond rock cutting tool. On the basis of the proposed procedure the authors analyze and operating influences to preserve the set and optimum deepening per a revolution are revealed under effective destruction of firm rocks. The estimation method of stress-strain state of rocks to be drilled and the choice of the maximum axial load in diamond drilling of rocks with different physical and mechanical properties.
\end{abstract}

\section{INTRODUCTION}

Optimization of drilling modes, improvement and creation of new high-performance rock destruction tools should play a big role in solving the problem of increasing drilling speed. Successful development of drilling technique and technology requires in-depth knowledge of patterns of the rock behavior at the well opening, patterns of rock destruction by the rockdestroying tool, structures, operation and wear of this tool. Thus, the study of the mechanics of bottomhole processes, methods of describing and calculating these processes will allow to develop an effective technology of the rock destruction.

The actual task in the current drilling conditions is to predict the drilling strength of rocks, to determine the concepts of choosing the drilling method and the rock-destroying tool in each individual case. The search for new ways to improve the efficiency and quality of drilling operations without increasing the energy consumption and resource of the rock-destroying tool by modernizing the drilling technology on the example of the method of optimizing the axial load is important for scientific and practical significance.

The problem of evaluating the limit state of rocks to be drilled can be categorized to the group of problems, where the main criteria for the solid body state are excessive crack opening or its complete destruction.

The main resistance parameter of rocks to be drilled is its normative resistance (tensile strength, yield strength, critical resistance, etc.), which determine the level of the maximum axial load on the rock-cutting tool.

\section{MATERIALS AND METHODS}

To assess the stress-strain state of rocks to be drilled and select the maximum permissible axial load for effective rock destruction in the drilling process, the flat problem solution (one of the 
main stresses is zero) of elasticity theory is most often used, at the same time the rocks at the bottom of the well experience normal vertical stress $\sigma_{x}$ (Figure 1), normal lateral compression stress $\sigma_{y}$ in the horizontal direction and shear stresses $\tau_{x y}$ that determine the adhesion of rocks during their destruction.

The above-mentioned normal stresses relate to each other according to the dependence:

$$
\sigma_{y}=\frac{1-\mu}{\mu} \cdot \sigma_{x}=\lambda \cdot \sigma_{x}
$$

where $\mu$ is the Poisson's ratio for the rock to be drilled; $\lambda$ is the lateral compression ratio.
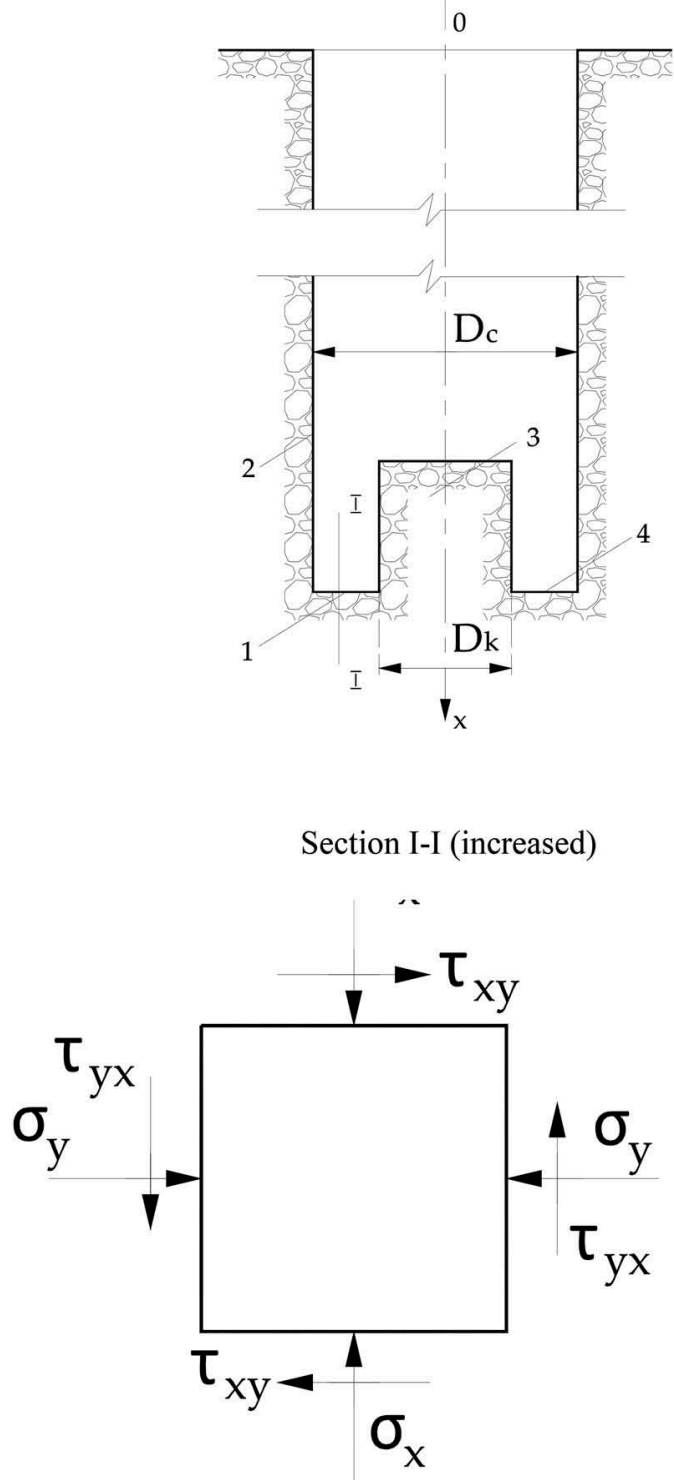

Figure 1. Calculation scheme for determining bottom-hole rock stresses, where: 1-the element of the array to be drilled allocated to the bottom; 2-the walls of the well; 3-the core column; 4-the bottom of the well; $\sigma_{x}$ and $\sigma_{y}$ normal stresses; $\tau_{x y}$ and $\tau_{y x}$ tangential stresses on the surfaces of the array element to be drilled. 


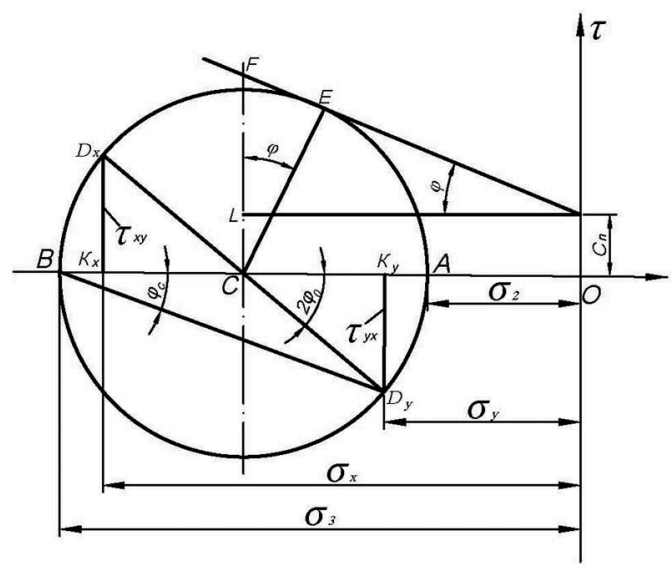

Figure 2. Graphical representation of stress distribution (Mohr circle) on the surfaces of an array element from the well bottom, where: $\sigma_{2}$ and $\sigma_{3}$-the main tension.

The relationship between the stresses $\sigma_{x}, \sigma_{x}$ and $\tau_{x y}$ can be obtained by constructing-for the case in question (see Figure 1) the corresponding Mohr circle (Figure 2), from which its understood that the envelope of the circle at the maximum level of the shear stress is spaced from the center of the circle at a distance

$$
\overline{F C}=C_{n}+\overline{F L}
$$

where $C_{n}$ the grip or the shifting strength of rocks.

If we take into account that

$\overline{F L}=\overline{O C} \cdot \operatorname{tg} \varphi$ and $O C=\frac{\sigma_{x}+\sigma_{y}}{2}$

we will have

$$
\overline{F C}=C_{n}+\frac{\sigma_{x}-\sigma_{y}}{2} \cdot \operatorname{tg} \varphi
$$

The radius of the Mora circle

$$
\overline{C D_{x}}=\overline{E X}
$$

then

$$
\overline{C D}_{x}=\overline{F C} \cdot \cos \varphi=C_{n} \cdot \operatorname{Cos} \varphi+\frac{\sigma_{x}+\sigma_{y}}{2} \cdot \sin \varphi
$$

where $\varphi$ is the angle of internal friction of the target rock.

From a triangle $C D_{x} K_{x}$ (see Figure 2) it follows that, in turn,

$$
\overline{C D_{x}}=\frac{\overline{D_{x} K_{x}}}{\sin 2 \varphi_{0}}=\frac{\left(\sigma_{x}-\sigma_{y}\right) \cdot \operatorname{tg} 2 \varphi_{0}}{2 \cdot \sin 2 \varphi_{0}}=\frac{\sigma_{x}-\sigma_{y}}{2} \cdot \cos 2 \varphi_{0},
$$

where $\varphi_{0}$-the angle of inclination of the area on which the stress acts $\sigma_{x}$, to the greatest main stress; $0<\varphi_{0}<0,8$ on average, $0.3 \mathrm{rad}$ for most cases of drilling in hard rocks are used $\varphi_{0}=$. 
Equating the right parts of expressions (2) and (3), we obtain

$$
\sigma_{x}=\frac{2 C_{n} \cos \varphi+\sigma_{y}\left(\sin \varphi+\cos 2 \varphi_{0}\right)}{\cos 2 \varphi_{0}-\sin \varphi}
$$

Or

$$
\sigma_{x}=\frac{2 C_{n}+\sigma_{y}(K+2 \operatorname{tg} \varphi)}{K}
$$

where $K$ is the reducing factor:

$$
K=\frac{\cos 2 \varphi_{0}-\sin \varphi}{\cos \varphi}
$$

Substituting the value $\sigma_{y}$ of the dependence (1) in the expression (4) and after some transformations we finally get

$$
\sigma_{x}=\frac{2 C_{n}}{K-\lambda(K+2 \operatorname{tg} \varphi)}
$$

The area of the contact surface on which the stress acts $\sigma_{x}$ is equal to

$$
f_{k}=\alpha \frac{\pi}{4}\left(D_{c}^{2}-D_{k}^{2}\right)
$$

Where $\alpha$-the coefficient characterizing the size of the cutters contact total area ratio with the cross-sectional area of the annular face of the well; for crowns with a diameter of 59 and $76 \alpha=0,06 \div 0,10 \mathrm{~mm}$, i.e. on average it is possible to use $\alpha=0,08 ; D_{c} \Pi D_{k}$-diameters of the well and core respectively.

Taking into account the expressions (6) and (7), we can write the expression for the maximum axial load on the well bottom during core drilling

$$
P_{n p}=\sigma_{x} \cdot f_{k}
$$

Or

$$
P_{n p}=\frac{\alpha \cdot \pi \cdot C_{n}\left(D_{c}^{2}-D_{k}^{2}\right)}{2[K+2 \operatorname{tg} \varphi]}
$$

The adhesion of rocks $C_{n}$ in the formula (8) can be expressed through the strength of rocks on uni-axial compression $\sigma_{\mathrm{cж}}$ and the coefficient of internal friction $\varphi$ (Bock, 1983):

$$
C_{n}=\frac{\sigma_{\text {сж }}}{2 \operatorname{tg}\left(\frac{\pi}{4}+\frac{\varphi}{2}\right)} .
$$

\section{RESULTS AND DISCUSSION}

Using the given calculation method, it is possible to determine the maximum axial loads during drilling of rocks with different physical and mechanical properties and different drilling capacity. 
Table 1. Physical and mechanical properties of rocks.

\begin{tabular}{|c|c|c|c|c|c|c|c|}
\hline № & $\begin{array}{l}\text { Formation } \\
\text { rock }\end{array}$ & $\begin{array}{l}\text { modulus of elasti- } \\
\text { city } E, 10^{5} \mathrm{MPa}\end{array}$ & $\begin{array}{l}\text { Poisson's } \\
\text { ratio, } \\
\mu\end{array}$ & $\begin{array}{l}\text { coefficient of } \\
\text { lateral } \\
\text { compression, } \\
\lambda\end{array}$ & $\begin{array}{l}\text { One-axial com- } \\
\text { pressive strength } \\
\sigma_{\text {сж⿱ }}, M P A\end{array}$ & $\begin{array}{l}\text { Internal } \\
\text { friction } \\
\text { angle } \\
\varphi, \text { grad. }\end{array}$ & $\begin{array}{l}\text { Rock } \\
\text { adhesion } \\
C_{n}, M P a\end{array}$ \\
\hline 1. & Basalt & 1,0 & 0,28 & 0,39 & 290 & 50 & 52,7 \\
\hline 2. & Granit & $0,55-0,9$ & 0,25 & 0,33 & 210 & 48 & 40,3 \\
\hline 3. & Gabbro & 1,05 & 0,34 & 0,51 & 200 & 46 & 40,4 \\
\hline 4. & Limestone & $0,2-0,9$ & 0,22 & 0,28 & 110 & 50 & 20,0 \\
\hline 5. & Sandstone & $0,1-0,7$ & 0,30 & 0,43 & 105 & 47 & 20,7 \\
\hline 6. & Hard shale & 0,4 & 0,25 & 0,33 & 75 & 45 & 15,6 \\
\hline 7. & Siltstone & 0,3 & 0,26 & 0,35 & 60 & 43 & 13,0 \\
\hline 8. & Argillite & 0,2 & 0,24 & 0,32 & 45 & 42 & 10,0 \\
\hline
\end{tabular}

Table 2. Ultimate axial loads of some rocks during drilling by diamond crowns with diameters of 59 and $76 \mathrm{~mm}$.

\begin{tabular}{|c|c|c|c|c|c|c|}
\hline \multirow[b]{2}{*}{ № } & \multirow[b]{2}{*}{$\begin{array}{l}\text { Formation } \\
\text { rock }\end{array}$} & \multirow{2}{*}{$\begin{array}{l}\text { Category of } \\
\text { rocks by } \\
\text { drillability }\end{array}$} & \multirow{2}{*}{$\begin{array}{l}\text { Shorthand } \\
\text { multiplier } \\
\mathrm{K}\end{array}$} & \multirow[b]{2}{*}{$\begin{array}{l}\sigma_{x} \\
\mathrm{MPa}\end{array}$} & \multicolumn{2}{|c|}{$\begin{array}{l}\text { Maximum axial loading, } \\
\mathrm{kN}\end{array}$} \\
\hline & & & & & $\begin{array}{l}\text { Calculation results } \\
\mathrm{P}_{\text {пр }}\end{array}$ & Recommendations [4] \\
\hline 1. & Basalt & $\mathrm{X}$ & 0,71 & 127,9 & $7-15 / 11-19$ & $8-15 / 12-17$ \\
\hline 2. & Granit & IX - X & 0,199 & 134,3 & $8-16 / 12-21$ & $8-15 / 12-17$ \\
\hline 3. & Gabbro & IX & 0,233 & 85,8 & $6-11 / 8-14$ & $6-12 / 8-13$ \\
\hline 4. & Limestone & VII - VIII & 0,171 & 73,5 & $5-9 / 7-12$ & $6-8 / 8-12$ \\
\hline 5. & Sandstone & VII & 0,213 & 51,8 & $4-7 / 5-9$ & $4-8 / 5-10$ \\
\hline 6. & Hard shale & VII & 0,239 & 62,4 & $4-8 / 6-10$ & $4-8 / 5-10$ \\
\hline 7. & Siltstone & VI & 0,265 & 54,0 & $4-7 / 5-9$ & $4-8 / 5-10$ \\
\hline 8. & Argillite & V - VI & 0,279 & 51,8 & $4-7 / 5-8$ & $4-7 / 5-8$ \\
\hline
\end{tabular}

As an example, Table 1 shows the data of physical and mechanical properties (Bulychev, 1989; Gorshkov, 1992) calculations of some rocks, drilled by diamond crowns, and in Table 2-values of limit axial loads for the same rocks drilled with crowns of $59 \mathrm{~mm}$ (in the numerator) and $76 \mathrm{~mm}$ (in the denominator) diameters in comparison with other data (Gorshkov, 2000).

From Table 2 conclusions can be made that the limiting axial loads calculated by the proposed method are satisfactorily correlated with their values obtained experimentally from the device "ВИТР". Some deviations of the compared data are explained by inaccuracies in determining the coefficient of internal friction of rocks and the value of the lateral compression coefficient, depending both on the depth of the well in the drilling interval and on geological and tectonic conditions, as well as a fairly rough averaging of the coefficient $\alpha$ in formula (7), which is determined by the level of bulky diamond saturated crowns (Gorshkov, 1992).

\section{CONCLUSIONS}

Using of the described technique, it is possible to determine the most optimal operating conditions of the rock-destroying tool.

The validity of the technique is confirmed by the close convergence of the results of the theoretical and experimental studies. The statistical evaluation of the results of the experimental 
studies showed that the error is not more than 5\%. Nevertheless, the calculation showed sufficient simplicity and practical applicability of the proposed method for determining the maximum permissible axial loads in diamond drilling, at least at the preliminary stage, which is confirmed by the results of the study (Blinov et al., 1983).

\section{REFERENCES}

Bock H. Introduction to the mechanics of rocks. - M .: Mir, 1983.

Bulychev N.S. Mechanics of underground structures in the examples and tasks. - M .: Nedra, 1989.

Gorelikov V.G. The classification and analysis of the methods of determining the diamond's number involved in the destruction of rock/Yu.V. Lykov, Baatarkhuu Gantulga. The collection of the master and postgraduate student's research, 2014. № 9/156, - pp. 115-117.

Gorshkov L.K. Temperature modes of diamond drilling/L.K. Gorshkov, V.G. Gorelikov.- M.: Nedra, 1992. - p. 73.

Gorshkov L.K. Assessment of the stress-strain state of the diamond crown matrix during dynamic interaction with a mountain massif/L.K. Gorshkov, V.I. Spirin// Collection of "Geological study and use of the subsoil", Vol. 3. - M .: Geoinformmak, 2000. - p. 3-14.

Neskoromnykh V.V. Rock destruction in geological survey. [Razrushenie gornyh porod pri provedenii geologo-razvedochnyh rabot]. Uchebnik-Textbook. Krasnoyarsk: Publ.H. SFU, 2012, 297 p.

Reference guide of the master exploration drilling/ G.A. Blinov, V.I. Vasiliev, Yu.V. Baklanov and others. - L .: Nedra, 1983. 